\title{
Implicit Learning and Explicit Learning in the Context of Teaching Chinese as a Foreign Language-By Analyzing the Textbook Kuaile Hanyu*
}

\author{
YU Le-le \\ North China University of Technology, Beijing, China
}

\begin{abstract}
With the rising status of China in the world in the economic, political and cultural aspects, Teaching Chinese as a Foreign Language (TCFL) is becoming more and more prevalent across the world. Britain is the country where the Chinese is taught and learnt earlier than other Western countries. Take the students in Confucius Institute of Newcastle University in UK for example, due to the students' different backgrounds and also different ages and language foundations, whether the Chinese teaching materials can meet their motivations and needs is a problem worth further investigation by Chinese language teachers. Therefore, concerning the learners' different ages and cognitive ability, this paper aims to analyze the textbook named Kuaile Hanyu (Happy Chinese) in terms of its advantages and disadvantages, in hope to evaluate whether it is appropriate to different learners and propose a few suggestions for the Chinese materials in the future. Simultaneously, from perspective of implicit learning and explicit learning, a tentative study is carried out on the influence of implicit and explicit learning in TCFL context.
\end{abstract}

Keywords: Teaching Chinese as a Foreign Language (TCFL), textbook, implicit learning, explicit learning

\section{Introduction}

In 1825, the British professor and scholar Robert Morrison, to be the first Chinese teacher, taught Chinese in London. And in 1938, University of London set up Chinese course, which made Teaching Chinese as a Foreign Language (TCFL) be accepted officially in the UK universities (ZHOU, 2005). So far, Chinese teaching has become a mainstream in the secondary and primary schools of Britain rather than an unnoticed course just in a few universities in the past. Obviously, the demand of Chinese teaching material is becoming increasingly higher and higher year by year. However, some problems emerged in the development of TCFL.

This study is practical in that it will identify the typical problems of the textbooks by comparing the implicit and explicit learning. In the process of further investigation, it is expected that the findings could make some contributions to the improvement of Chinese textbooks in TCFL context, which definitely is of great significance not only for teaching but also for learning.

\footnotetext{
* This paper is funded by "North China University of Technology Cultivation for Outstanding Young Teachers Program”: study on the Chinese teaching as a second language in China, Japan, English-speaking countries, and Germany.

YU Le-le, lecturer, master, English Department, North China University of Technology.
} 


\section{Introduction of Kuaile Hanyu}

\section{The Development of Textbook-Kuaile Hanyu}

The aim of Chinese teaching materials is not only to facilitate the learners to acquire the language, but also to benefit them to get to know about the Chinese culture. With a lot of successful concepts and methods in this book, Kuaile Hanyu (English Version) is also applied by many Confucius Institutes in Britain. After soliciting opinions from the experts concerned and with the permission of NOCFL (China National Office for Teaching Chinese as a Foreign Language), the textbooks have been published in the UK by the British Council with the title Chinese for GCSE (General Certificate of Secondary Education) (2002). In 2003, it was named Kuaile Hanyu (International Version). In 2006, it was elected to be the most popular "International Chinese Teaching Materials” out of other numerous teaching materials. In 2009, to meet the learners' needs in different countries, it has been translated into several languages including English, French, German, Japanese, Korean, and Italian. In 2010, it was honored as "The Excellent International Chinese Teaching Material" in the competition of international Chinese teaching materials, which is prevalently used by the teachers and learners in domestics and abroad. Therefore, this teaching material is worth further investigation in this paper.

\section{The Content and Structure of the Teaching Material}

Kuaile Hanyu (English Version) is a series of Chinese teaching materials specially compiled for junior middle school students aged from 11 to 16 whose mother tongue is English. The set consists of a student's book, a teacher's book, a workbook, flash cards, and CDs. Kuaile Hanyu is made up of three levels with six books, each of which contains eight units with three texts related to the same topic. At the end of each unit, Character-writing exercises are also incorporated in the student textbooks. Audio CDs accompany each book and there is ample scope for children to gain listening and comprehension practice.

With both a student's book and teacher's book at each level, Kuaile Hanyu accords with learner's psychological conditions and needs of the student from 11 to 16 years old, and with the requirements of foreign language curricula of certain countries. Kuaile Hanyu (Happy Chinese) engages students' interest straight away through the use of appealing cartoon personalities, colorful cartoons and photographs. The dialogue situations are life-like, relevant, drawn from areas such as family, school, environment, and sports and so on. It is suitable for conversational exercise of primary and secondary school students; with the practical contents designed for versatile usages, it is very popular among teachers and students. The emphasis is on enabling the students to learn Chinese in natural conditions and to arouse their interest and to raise their ability to communicate in Chinese, so as to lay a solid foundation for their studies.

\section{The Introduction of Implicit Learning and Explicit Learning}

Since the 1950-1960s of last century, TCFL has drawn great attention in Western countries. From 1950 to 2014, the papers concerning TCFL characters research has reached to 398. Thus, many textbooks have much emphasis on characters teaching. As cognitive psychology pointed out that implicit learning and explicit learning have been applied to TCFL in recent years. This paper is to explore characters teaching in terms of implicit and explicit learning based on the textbook of Kuaile Hanyu. Before exploring the characters exercise, it is appropriate to illustrate what the implicit and explicit learning is respectively. 
American cognitive psychologist Reber (1967) has proposed the conception of implicit learning in “Artificial Grammar Implicit Learning”. He also stated that there are two types of learning, that is, implicit and explicit learning. He believed that implicit learning means that learners are unaware of the structure of the knowledge that they learn, however, unconsciously and unknowingly, they acquire the knowledge through comprehensible input. On the contrary, explicit learning is a process of making effort and study strategies to complete tasks.

From the perspective of ages, a baby can acquire his mother tongue without any difficulty while an adult is unable to become a proficient foreign language learner. Thus, it is essential to understand the differences between implicit and explicit learning both from theoretical and practical perspective, which will make Chinese character teaching more effective to combine the two kinds of learning patterns appropriately.

\section{Research Question}

The contemporary overseas Chinese teaching is chaotic, to be more specific, it is a common phenomenon that the same textbook is used in both universities and high schools, or even in junior or senior schools (H. XU, 2009). Due to different ages, backgrounds, professions, and study habits, it can be seen that the cognitive ability between adults and children is bound to be different. Whether the same textbook can meet the needs and motivations of these different learners? It should be analyzed and investigated further.

\section{The Significance of Analyzing Exercise in Textbook}

In the process of compiling, the textbooks were tried out in some junior middle schools in UK under the organization of the British Council. Kuaile Hanyu, aiming to train Chinese communicative competence in the real-life environment, motivates and stimulates the learners' interest. As in most Chinese-published material, the emphasis is on direct immersion in language exercises, and there are a large number of exercises for each new part.

The director of the center for British Chinese resources Chen Tongdu in the China National office believes that the current textbooks with the writers' self-concepts and methods are not able to meet the learners' different requirements and needs based on their backgrounds, ages, and language levels.

As YANG Hui-yuan (1997) noted that language acquisition is achieved through doing exercise rather than being taught or told. To some extent, passing on the knowledge is just to make the learners to know, on the contrary, practice can achieve the goal of understanding. It is obvious that the exercises attached to each unit seem very effective and efficient for learners' language acquisition. It is of great significance to analyze the character exercises in an implicit and explicit method concerning the student's different ages and backgrounds.

\section{The Analysis of Character Exercise}

\section{Form}

According to LIU Xun (2000), the exercise of sentence pattern substitute in many teaching materials, generally speaking, is simply to list the new vocabulary, which seems boring and dull. ZHAO Jin-ming (1998) also pointed out that the exercises of Chinese teaching material are tedium with insufficient quantity. From the perspective of the author, excessive exercises will cause students' tiredness; on the other hand, limited amount of 
exercises could have a negative effect on students' language acquisition. Compared with the practice of sentence pattern substitute in Kuaile Hanyu, most of the contents are picture talks or choice-making according to the pictures, which are very interesting and vivid. Practice is no longer the inflexible presentation of the language structure, and the students do not necessarily complete the exercise passively and mechanically but their emotions and interest could be stimulated. Thus, the form of exercise is attractive to both youngsters and adults.

\section{Tones}

Chinese characters teaching should follow the basic steps such as "recognition" and "stroke", "write", "apply" so that the students can gradually master the form, sound, meaning, and usage of Chinese characters. The practice in this textbook is not enough, at the same time, because the emphasis in Kuaile Hanyu is on learning characters and pinyin together; the pinyin pronunciation appears above each character in small text (grouped as a compound where appropriate), providing a more friendly approach for children but not proper for the adults. Additionally, the characters which have the same form but different tones are also what the learners' problem.

\section{Strokes}

What worries the majority of foreign learners is the writing of Chinese character, especially the strokes. When analyzing the textbook Kuaile Hanyu, stokes of the Chinese characters are marked with different colors, which make the learners to be clear about the sequence of the strokes when writing Chinese characters. From this point of view, it is beneficial to the beginners, especially the younsters, who often make mistakes of writing. However, it is omitted in the third volume (WANG, 2000). Compared with the youngsters in middle school, it is suitable and appropriate for the adult learners who should strengthen the structure of Chinese characters and components. The more challenges there are, the more motivations they will obtain.

\section{The Analysis of the Quantity of Exercise}

As shown in Figure 1, the quantity of the exercise in the three textbooks has been analyzed. Take the characters practice into example, the numbers in the first textbook are from five to eight. Alternatively, the numbers in the second textbook is seven; however, the numbers in the third shows a tendency of decrease, which is from five to seven. Combining the numbers of the exercises in three textbooks, the distribution and outline is relatively reasonable. As scholars XU Zi-Liang (1999) advocated a saying "sense of the word”, he suggested that it is efficient to expose students to as many characters as possible and to help students experience and perceive the shape of Chinese character by practicing extensively, especially in the initial stage. Therefore, the students could shape and form the sense of the word by expanding the scope of short-term memory.

It can be concluded that the number is decreasing in the third year, which shows that the foundation has been laid in the first two years. Students should focus on their study in the initial process of language learning with sufficient and adequate drills of the exercises.

As it is shown in Figure 2, the quantity of the exercises shows a tendency of decrease. However, it should be admitted that it shows an irregular result, more specifically, the numbers of the first book is 155, the numbers of the second book is 169, and the third book is 134 subsequently. From this perspective, with the increase of autonomous learning, it should be admitted that it is suitable for the learners' cognitive features.

In terms of the difficulty, it can be concluded that basic grammar practice is emphasized and consolidated, 
while the second book prefers the usages of vocabulary and the training of sentence patters flexibly, and in the third book, both of the difficulty and variety are more challenging. Therefore, with the enhancement of the learner's autonomous ability and the independent ability, it is in line with the learning characteristics and cognitive features of learners.

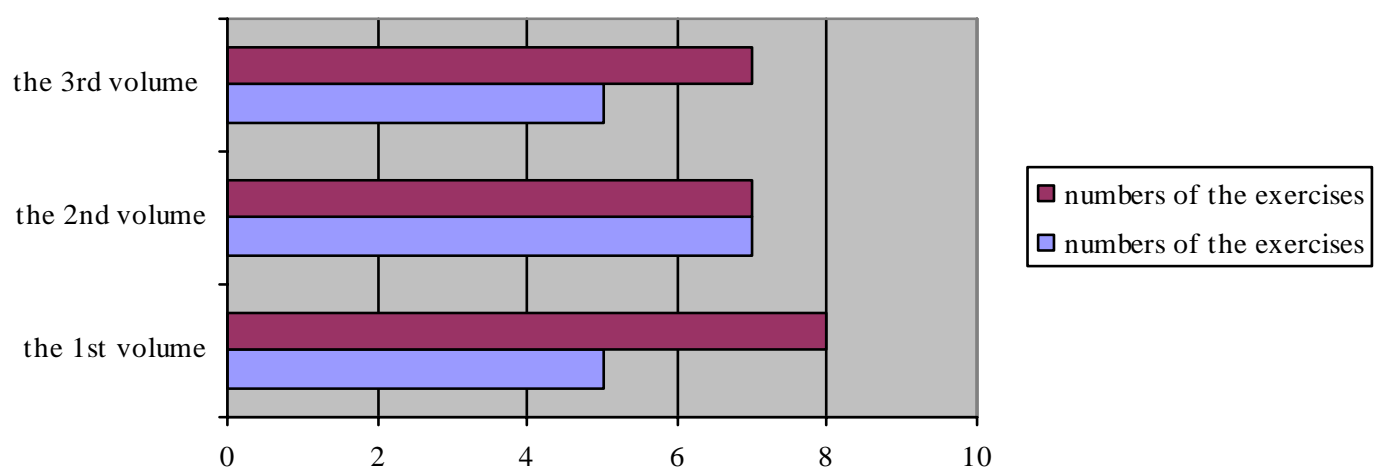

Figure 1 . The quantity of the exercise in the three textbooks.

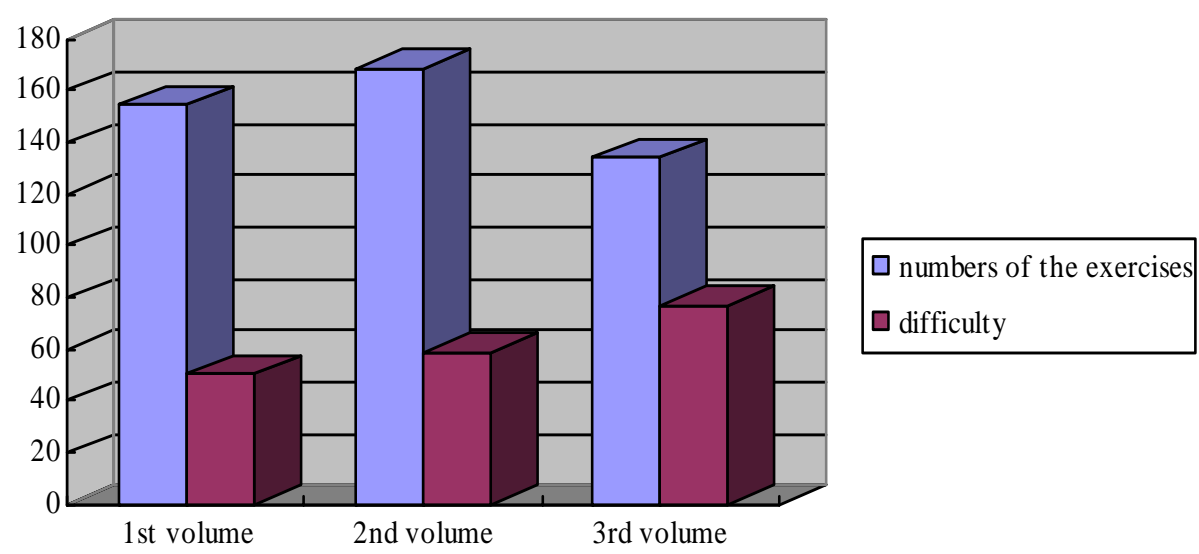

Figure 2. The quantity of the exercise and the degree of the difficulty.

Explicit learning, for example, vocabulary or grammar leaning, is completed by explicit means such as memory and syntax analysis through a conscious way, more specifically, the acquired knowledge is stored in an explicit way and controlled by consciousness while implementing.

\section{Findings}

Based on what have been analyzed above, it can be concluded that the practical teaching material can play a prominent role in terms of teaching quality. When assessing the effectiveness and efficiency of a textbook, many factors should be taken into account, for example, whether the contents of textbooks should be suitable for the students' language level, whether it caters for the learners according to their ages, whether it can meet the needs and learning purpose of learners' based on their different language proficiency, whether it can properly deal with the problems between language and culture. However, most of the Chinese textbooks are teacher-centered rather than the students-centered so that the textbooks cannot get close to foreign learners' thinking due to lack of foreign culture, language, and expressions. 
The results concluded that in the first volume of Kuaile Hanyu, the total words are 178, 71\% of which are the new HSK (level 1), (level 2) words. The numbers of characters which have the same form but different tones in Kuaile Hanyu are 299 characters. Obviously, Kuaile Hanyu embodies requirements of the "syllabus" and "levels" of HSK in terms of characters. No matter what textbook the learners will learn, they will gain access to these Chinese characters.

From the perspective of the connection between implicit learning and Chinese character teaching in Kuaile Hanyu, based on dynamic composition corpus, there are many mistakes such as joined up, misplacement, mismatch, wrong radicals, which reflect that there exist certain disadvantages in terms of the implicit learning.

\section{Suggestions}

\section{The Roles of Teachers}

The impact teachers have on learners is significant, especially on the junior students. To be more specific, teachers in the primary stage should change some of the strategic approaches, for example, to strengthen the relationship between a combination of strokes and Chinese characters. When teachers write Chinese on the blackboard and correct homework, they should write the words clearly so as to avoid "joined up”. In this way, students are not only clear about the numbers of the strokes but also form a habit of writing characters more clearly, for instance, the stroke of the word "home" is complicated, especially its radical, so the stokes like this should be paid more attention to.

\section{Strengthening Explicit Teaching}

The implicit teaching method implemented in the teaching material is to make the students form a sense of the words unconsciously, thus gradually and eventually acquire these characters. In the process implicit learning, students are able to master the overall structure of these characters, for example, the left and right structure, or the up and down structure. It is a wrong conception that students can get a better grasp of the overall structure. To reduce these errors, we should begin to teach, such as strokes and radical, enable students to focus on the details, especially when there is the same kind of stroke for many times.

\section{Conclusion}

The Confucius institutes abroad are hoping to assist Chinese government promoting Chinese learning and dissemination of Chinese culture. A large number of volunteers and professional Chinese teachers have been sent to overseas to carry out Chinese language teaching, simultaneously, numerous teaching materials and documents have been introduced from domestic. When confronted with such a variety of Chinese textbooks, whether they can really serve learners effectively and efficiently and whether they can meet the learners' needs are worth of exploring and analyzing by our language teachers.

This paper is to analyze the characteristics of teaching material named Kuaile Hanyu in the perspective of ages, backgrounds, and cognitive ability of learners. By comparing the similarities and differences between Kuaile Hanyu and other Chinese textbooks, the author proposes some suggestions and recommendations.

It also can be concluded that the communication between editors and users is of great necessity in order to investigate the problems emerged in the process of application and then to resolve the problems and adapt the textbooks. 
Meanwhile, the textbook editor should focus on learner's characters including their Chinese levels, their identity, cognitive characteristics, ages, specially the understanding of the local language, culture, and the actual situation of the overseas Chinese learning should also be taken into deep consideration in order to meet the needs of the different levels of Chinese language learners, to achieve high quality of the teaching effect, and to improve the teaching material constantly and appropriately.

\section{References}

Hanban (NOCFL). (2003). Happy Chinese (Volume 1) and its practice. Beijing: People’s Education Press. LI, Q. (2006). Research in textbook of Chinese as foreign language. Beijing: The Commercial Press.

LIU, X. (2000). An introduction of Chinese as foreign language pedagogy. Beijing: Beijing Language and Culture University Press. LV, B. H. (2007). Han Hongyu second language teaching. Beijing: Pecking University Press.

Reber, A. S. (1967). Implicit learning of artificial grammars. J Verb Learn Verb Be, 6, 56.

SONG, L. N. (2002). Chinese studies in the United Kingdom: 2002 overview. Retreieved from http://www.Lang.ltsn.ac.UK/ resources/materials bank Aspx?resourceid/1452

TONG, B. Z. (1991). The writing of the primary Chinese textbooks. The world of Chinese teaching, (3), 178.

WANG, X. J. (2000). Chinese characters teaching and Chinese language acquisition. Chinese Language Teaching Journal, (4).

XIAO, X. Q. (1994). The Chinese character teaching and textbook compilation issues. Chinese Teaching in the World, $30(04), 68$. XU, H. (2009). International Chinese language education. Beijing: Foreign Language Teaching and Research Press.

XU, Z. L. (1999). The practical method of teaching Chinese as a foreign language. Beijing: Pecking University Press.

YANG, H. Y. (1997). Introduction to the study of teaching Chinese as a foreign language. Peking: Beijing Language and Culture University Press.

ZHAO, J. M. (1998). Evaluation on teaching Chinese as a foreign language. Beijing: Language Teaching and Linguistic Studies. ZHOU, S. J. (2005). Dynamic Chinese teaching in England. Chinese Language Teaching Journal, (1). 